Article

\title{
Solid-Phase Synthesis of Azole-Comprising Peptidomimetics and Coordination of a Designed Analog to $\mathrm{Zn}^{2+}$
}

\author{
Aanchal Mohan, Allyson H. M. Koh, Gregory Gate ${ }^{(\mathbb{D})}$, Anna L. Calkins, Kyra N. McComas and \\ Amelia A. Fuller* (D) \\ Department of Chemistry \& Biochemistry, Santa Clara University, Santa Clara, CA 95053, USA; \\ mohanaanchal1@gmail.com (A.M.); allysonkoh21@gmail.com (A.H.M.K.); gate@ucsb.edu (G.G.); \\ acalkins@scu.edu (A.L.C.); sparky6578@msn.com (K.N.M.) \\ * Correspondence: aafuller@scu.edu; Tel.: +1-408-554-4316
}

Academic Editor: Viktor Krchnak

Received: 6 April 2018; Accepted: 26 April 2018; Published: 28 April 2018

\begin{abstract}
Peptidomimetics that can coordinate transition metals have a variety of potential applications as catalysts, sensors, or materials. A new modular peptidomimetic scaffold, the "azole peptoid", is introduced here. We report methods for the solid-phase synthesis of eleven examples of trimeric $N$-substituted oligoamides that include oxazole- or thiazole-functionalized backbones. The products prepared comprise a diversity of functionality, including a metal-coordinating terpyridine group. The modular synthetic approach enables ready preparation of analogs for specific applications. To highlight a potential use of this new synthetic scaffold, a trimeric azole peptoid functionalized with a terpyridine residue was prepared and studied. The characteristic 2:1 ligand:metal binding of this terpyridine-functionalized azole peptoid to $\mathrm{Zn}^{2+}$ in aqueous solution was observed. These studies introduce azole peptoids as a useful class of biomimetic molecules for further study and application.
\end{abstract}

Keywords: peptidomimetic; oligoamide; heterocycle; metal coordination

\section{Introduction}

One function of natural biopolymers that researchers have sought to recapitulate with modular, bio-inspired oligoamide scaffolds is the ability to coordinate transition metals in aqueous solution. Metal-binding peptidomimetics have potential application as sensors [1,2] or catalysts [3,4], for example. Naturally-occurring molecules, including peptides and peptide-derived natural products, frequently feature well-defined three-dimensional structures that display ligands in a specific arrangement to coordinate to metals. Synthetic oligoamides (i.e., peptidomimetics) offer similar capabilities to display functionality in a spatially controlled manner [5-8]. Non-natural peptidomimetics have the added advantage that well-studied metal-coordinating ligands not found in biomolecules (e.g., phenanthroline, bipyridine, hydroxyquinoline, or terpyridine) can also be appended $[9,10]$.

Azole metal-coordinating groups are commonly found in peptide-derived natural products [11]. For example, a number of azole-rich, macrocyclic peptide-derived marine natural products have been shown to bind to transition metals, including $\mathrm{Cu}^{2+}, \mathrm{Ag}^{+}$, and $\mathrm{Zn}^{2+}$ [12]. In the solid state structures of the copper complex with ascidiacyclamide and the silver complex with westiellamide, the azoles participate as coordinating groups $[12,13]$. There is interest in the preparation of analogs of this natural product group for a variety of uses, and most examples are macrocycles [14-16]. Nonetheless, syntheses frequently cannot easily accommodate the preparation of natural product 
analogs that include non-natural ligands. The inclusion of high-affinity non-natural ligands may allow for the discovery of synthetically tractable linear azole-rich oligoamides that bind to transition metals.

An attractive design for a new oligoamide biomimetic scaffold capable of transition metal binding would preserve the azole-rich features of metal-coordinating natural products and simultaneously accommodate the installation of diverse non-natural ligands with high affinity for metals. Of the available sequence-specific oligoamide scaffolds, peptoids ( $N$-substituted glycine oligomers, Figure 1) [17,18] are an especially useful starting point for design of a new peptidomimetic. Their efficient and modular synthesis enables a wide diversity of functionality to be displayed on the $N$-substitutent. Examples of peptoids that leverage the organized display of $N$-substituent functional groups to coordinate to metals have been reported [1,4,10,19-23]. Changing the oligo-glycine backbone unit to insert azoles between the methylene and carbonyl carbon would provide a strategy to prepare peptidomimetics that more closely replicate the metal-coordinating, azole-rich natural product structures. Additionally, this strategy could be compatible with introduction of non-natural ligands as $N$-substitutents. Recently, the inclusion of individual azoles (thiazole, oxazole) into peptoid backbones was reported [24], but an oligoamide with an all-azole backbone ("azole peptoids", Figure 1) is an unreported scaffold. The metal affinity of azole-comprising peptoids such as $\mathbf{9}$, studied here, has also not yet been evaluated. More broadly, the inclusion of azoles into oligoamide backbones is of interest to modulate various physicochemical features of oligomers, including their solubility, polarity, conformational heterogeneity, and hydrogen-bond accepting capabilities [24].

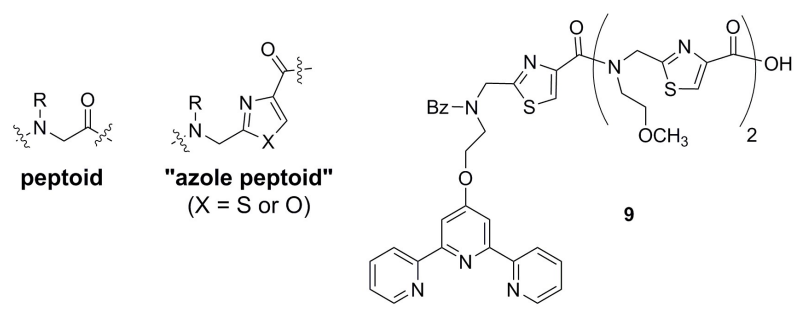

Figure 1. Examples of $N$-substituted oligoamide scaffolds, peptoids and "azole peptoids" described in this work, and the $\mathrm{Zn}^{2+}$-coordinating thiazole peptoid analog 9.

We hypothesized that sequence-specific azole peptoids that display a range of $N$-substituents, including metal-coordinating groups, would be synthetically accessible via modifications to the solid-phase peptoid submonomer synthesis. Here, we report the preparation of eleven examples of diverse trimeric azole peptoids, showcasing the flexibility of the synthesis of this new peptidomimetic. Additionally, we report coordination of the biologically relevant metal $\mathrm{Zn}^{2+}$ by terpyridine-functionalized thiazole peptoid 9 (Figure 1) in aqueous buffer.

\section{Results}

\subsection{Synthesis of Trimeric Azole Peptoids}

$N$-substituted oligoamides with an all-azole backbone ("azole peptoids") have not yet been reported, and we first sought to optimize conditions for their sequence-specific synthesis on solid support (Scheme 1). The commonly-used peptoid submonomer synthesis [25], wherein individual monomers are introduced by iterating bromoacetylation and amine displacement steps, has been modified to allow introduction of individual azole units into a longer oligoglycine backbone by replacing bromoacetic acid with a functionalized azole, 1 [24]. In the reported work, a large excess of 1 (10 equivalents) is used to introduce this backbone modification at the desired position in the peptoid, and both this reaction and the subsequent amine displacement of the chloride are promoted by microwave heating. Because $\mathbf{1}$ is prepared by a three-step synthesis (see Supplementary Materials), 
we wished to conserve the amount of $\mathbf{1}$ needed for the preparation of azole peptoids. Additionally, we sought methods that eliminated the reported microwave heating.

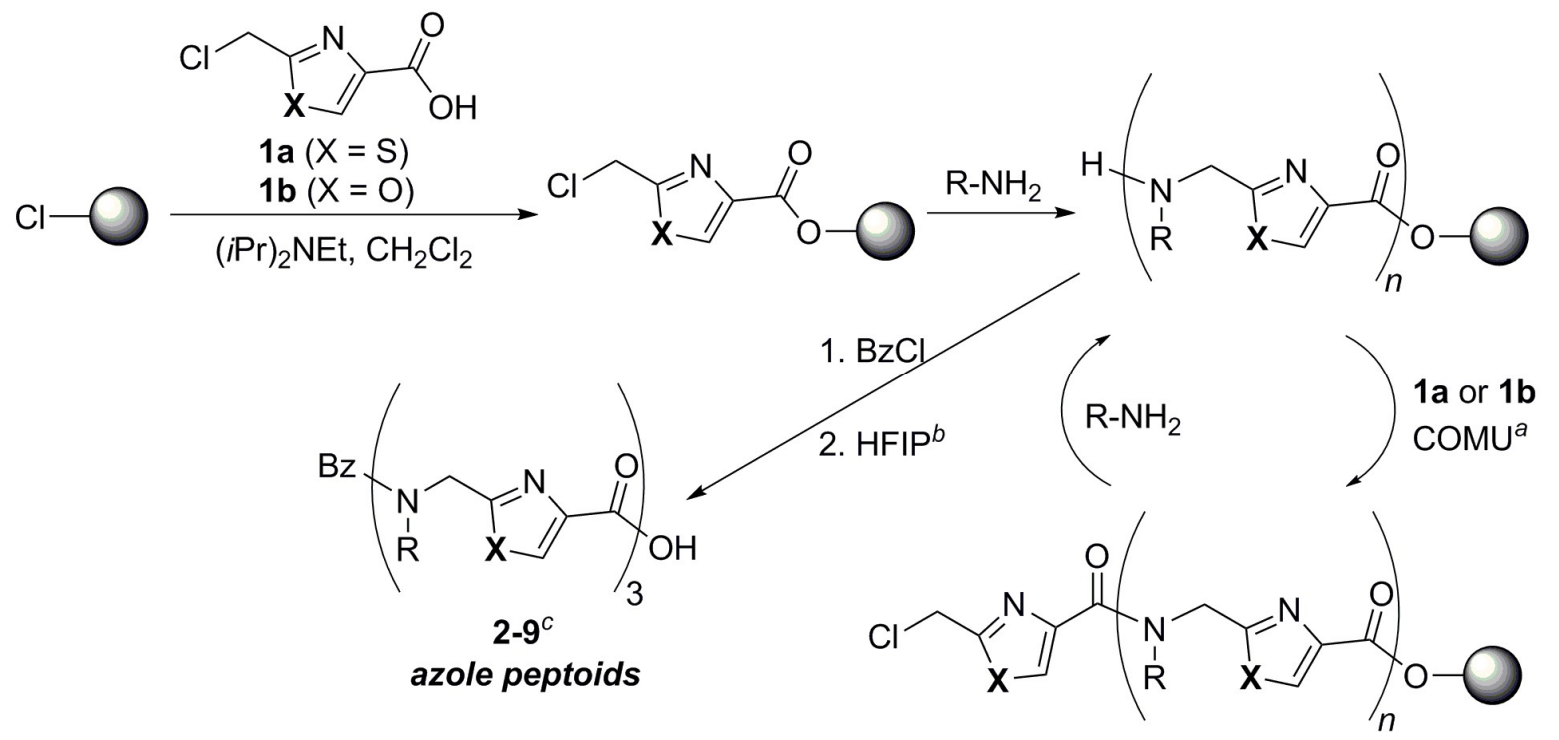

Scheme 1. Synthesis of trimeric azole peptoids on solid support. ${ }^{a}$ 1-[(1-(cyano-2-ethoxy-2oxoethylidene-aminooxy) dimethylaminomorpholino)] uronium hexafluorophosphate. ${ }^{b} 1,1,1,3,3,3-$ hexafluoro-2-propanol. ${ }^{c} \mathrm{R}$ group structures are detailed in Table 1.

To identify the optimal conditions for the synthesis of azole peptoids, we undertook the synthesis of the trimer-length azole peptoid 2a (see structure in Table 1), which is capped at the $N$-terminus with a benzoyl group. Synthesis of analogous $N$-substituted oligoamides, arylopeptoids was recently reported; an aromatic ring is inserted into the oligoglycine backbone [26]. We reasoned that the conditions for the preparation of arylopeptoids, which use modest excesses of the acylating reagent and no microwave heating, would be an excellent starting point for the efficient preparation of their counterparts containing azoles. 2-Chlorotrityl chloride resin was found to be suitable for the preparation of arylopeptoids and was used here as well. The progress of two critical synthetic steps in the synthesis of azole peptoid 2a was monitored using the chloranil test: the displacement of the terminal chloride with 4-(2-aminoethyl)morpholine, and the acylation of the intermediate secondary amine with 1a. The purities of crude products were assessed by analysis of reverse-phase high-performance liquid chromatography (RP-HPLC) data and compared to identify optimal reaction conditions. The amine displacement reaction was more efficient when heated, as expected. By comparing a small panel of reagents that mediate the $\mathrm{N}$-acylation reaction, we identified conditions that allow efficient reaction at room temperature with fewer equivalents of $\mathbf{1 a}$ or $\mathbf{1 b}$ than the reported procedure for the incorporation of $\mathbf{1 a}$ and $\mathbf{1 b}$ into peptoids [24]. We found that using 2.9 equivalents of 1-[(1-(cyano-2-ethoxy-2-oxoethylidene-aminooxy) dimethylaminomorpholino)] uronium hexafluorophosphate (COMU) and just 2.5 equivalents of the custom-synthesized reagent $\mathbf{1 a}$ in the acylation reactions provided $\mathbf{2 a}$ in $85 \%$ crude purity and $79 \%$ crude yield (Table 1). We evaluated other reagents to promote amide bond formation, including 1-[bis(dimethylamino)methylene]-1H-1,2,3-triazolo[4,5-b]pyridinium 3-oxido hexafluorophosphate (HATU) and bis-trichloromethylcarbonate (BTC), but these did not substantially improve the crude yields or purity of $\mathbf{2 a}$. Purification of $\mathbf{2 a}$ was subsequently effected by preparative RP-HPLC. 
Table 1. Yields and purities of trimeric heteroarylopeptoids prepared according to Scheme 1.

\begin{tabular}{|c|c|c|c|c|}
\hline Compound & Structure & Crude Yield & Crude Purity $^{1}$ & Isolated Yield $^{4}$ \\
\hline $\mathbf{2 a}(X=S)$ & & 2a: $79 \%$ & 2a: $85 \%$ & 2a: $61 \%$ \\
\hline $\mathbf{2 b}(\mathrm{X}=\mathrm{O})$ & & $2 b: 60 \%$ & $2 b: 60 \%$ & $2 b: 33 \%$ \\
\hline $3 \mathbf{a}(X=S)$ & & 3a: $58 \%$ & 3a: $81 \%$ & 3a: $13 \%$ \\
\hline $3 \mathbf{b}(\mathrm{X}=\mathrm{O})$ & & $3 \mathbf{b}: 79 \%$ & $3 b: 77 \%$ & $3 b: 31 \%$ \\
\hline $4 \mathbf{a}(X=S)$ & & 4a: $80 \%$ & 4a: $77 \%$ & 4a: $51 \%$ \\
\hline $4 \mathbf{b}(X=O)$ & & $4 b: 63 \%$ & $4 \mathbf{b}: 84 \%$ & $4 b: 48 \%$ \\
\hline 5 & & $65 \%$ & $89 \%$ & $40 \%$ \\
\hline 6 & & $52 \%$ & $80 \%$ & $15 \%$ \\
\hline 7 & & $110 \%^{2}$ & $98 \%$ & $63 \%$ \\
\hline 8 & & $\mathrm{ND}^{3}$ & $\mathrm{ND}^{3}$ & $39 \%$ \\
\hline 9 & & $67 \%$ & $\mathrm{ND}^{3}$ & $29 \%$ \\
\hline 10 & & -5 & - & - \\
\hline
\end{tabular}

\footnotetext{
${ }^{1}$ Determined by integration of crude HPLC chromatogram; ${ }^{2}$ Cleavage from resin and amine deprotection using $95 \%$ TFA, $2.5 \%$ triisopropylsilane, $2.5 \%$ water. Isolated yield $>100 \%$ is likely due to the presence of ammonium trifluoroacetate salt; ${ }^{3} \mathrm{ND}=$ not determined; ${ }^{4}$ Isolated yields were calculated following RP-HPLC purification;

${ }^{5}$ Yield was negligible using these conditions owing to incomplete acylation reactions.
} 
With optimal reaction conditions identified, we prepared and purified by RP-HPLC several other examples that comprise an assortment of functionality appended to the azole peptoid scaffold (Table 1). Acids $\mathbf{1 a}$ and $\mathbf{1} \mathbf{b}$ were used to prepare both thiazole and oxazole peptoid trimers, respectively. Reactions proceeded with comparably reliable reactivity for both heterocycles. Varying the primary amines used in the synthesis had more impact on overall yield and purities. However, a diversity of amine substituents was successfully introduced as appended azole peptoid side chains; neutral polar moieties (compounds 2-4 and 7-9), nonpolar groups $(5,6,8)$, and charged polar groups (7) can all be successfully installed. For the synthesis of 7 , the pendant amine functional group was protected as a $t$-butylcarbamate, and the protecting group was removed concomitant with cleavage of the molecule from the resin using 95\% TFA. Notably, we demonstrated with thiazole peptoid $\mathbf{9}$, which includes the terpyridine group, that well-studied metal-coordinating groups can be successfully installed. Disappointingly, the incorporation of the sterically demanding amines, such as $\alpha$-methylbenzylamine, provided negligible yields of the desired product 10; acylation of the sterically encumbered amine was problematic.

\subsection{Metal Coordination of $\mathbf{9}$ in Aqueous Buffer}

Given the successful synthesis of $\mathbf{9}$, which includes the terpyridine metal-coordinating ligand in the $N$-terminal position, we explored the potential for 9 to coordinate to the biologically important metal $\mathrm{Zn}^{2+}$. We monitored UV spectral changes to an aqueous solution of $\mathbf{9}$ as $\mathrm{Zn}^{2+}$ was titrated in (Figure 2). In the absence of metal, 9 has a maximum at $237 \mathrm{~nm}$ and broad shoulders at around 280 and $310 \mathrm{~nm}$. As metal was added to the solution, new spectral peaks emerged at 270, 309, and $320 \mathrm{~nm}$. A plot of the absorbance at the $320 \mathrm{~nm}$ maximum as a function of molar ratio of $9: \mathrm{Zn}^{2+}$ was generated to determine the ratio of the $9-\mathrm{Zn}^{2+}$ interaction (Figure 2 inset). The spectral changes at $320 \mathrm{~nm}$ plateau at $\left[\mathrm{Zn}^{2+}\right]:[9]=0.5$; one $\mathrm{Zn}^{2+}$ is coordinating to two molecules of 9. This plot looks similar when monitored at other wavelengths (data not shown). To ensure that the terpyridine functionality in 9 is essential for interaction with $\mathrm{Zn}^{2+}$, we collected UV spectra of an aqueous solution of $3 \mathbf{a}$ in the presence of increasing concentrations of $\mathrm{Zn}^{2+}$. In the absence of the terpyridine coordinating group, no spectral changes were observed upon addition of $\mathrm{Zn}^{2+}$ (see Supplementary Materials).

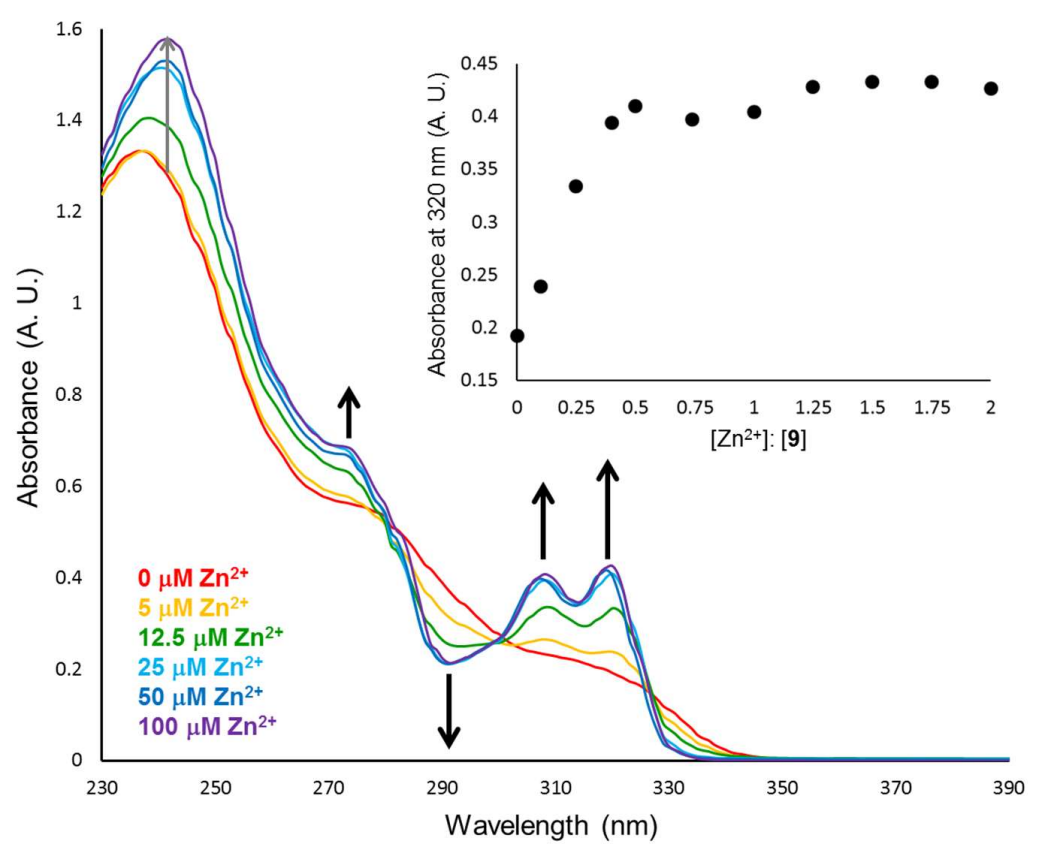

Figure 2. UV-Vis spectra of $50 \mu \mathrm{M} 9$ in the presence of varied concentrations of $\mathrm{ZnCl}_{2}$ in $10 \mathrm{mM}$ Tris buffer, $\mathrm{pH}$ 7.5. Arrows highlight spectral changes with increasing concentrations of $\mathrm{Zn}^{2+}$. The inset shows the change in absorbance at $320 \mathrm{~nm}$ as a function of the $\left[\mathrm{Zn}^{2+}\right]:[9]$ ratio. 


\section{Discussion}

The synthetic methods for azole peptoids optimized here have several advantages. Critically, the methods developed in this work conserve azole reagent 1 , which must be synthesized. The elimination of microwave-promoted synthesis steps previously reported for azole-functionalized peptoids is especially important for the preparation of examples that may coordinate to metals. Many potentially metal-coordinating $\mathrm{N}$-substituents include nucleophilic functionality that can undergo unwanted side reactions in the synthesis of peptoids or related oligomers [27]. Additionally, the conditions used for introduction of side chain functionality accommodate appending some nucleophilic side chains that are commonly problematic when used for synthesis of peptoids. For example, the nucleophilic nitrogen in the morpholine ring of 4-(2-aminoethyl)morpholine presents challenges when used as a peptoid submonomer [28]. However, it is an excellent submonomer for the synthesis of azole peptoids 2. Both the additional atoms of the azole in the peptoid backbone and the reduced reactivity of the chloromethyl group reduce the side reaction that is problematic in the synthesis of oligoglycine analogs.

Applying these synthetic methods, we have accessed a variety of analogs of a new biomimetic oligoamide. Differentially functionalized azole peptoids 7-9 highlight the modularity of the approach and the ability to install functionality sequence-specifically for custom applications. An attractive feature of this scaffold is that either $\mathbf{7}$ or $\mathbf{8}$ could be readily elaborated via chemoselective reactions with the amine or alkyne, respectively. We anticipate that adaptation of these methods by others will provide synthetic entry to custom azole peptoids that emulate motifs found in natural products or pharmaceuticals. Additionally, azole peptoids with varied lengths can be readily accessed, or combinatorial synthesis of azole peptoid libraries could be undertaken. Use of azole peptoids in screening campaigns could yield exciting applications for this new class of bio-inspired oligoamides.

The binding data obtained for 9 to $\mathrm{Zn}^{2+}$ closely matches those observed for homoleptic $\mathrm{Zn}^{2+}$-terpyridine complexes investigated by Würthner and co-workers [29]. As was observed in those studies, the lack of curvature in the binding titration plot (Figure 2 inset) precludes the determination of binding constants; the $\mathrm{Zn}^{2+}$-terpyridine affinity $\left(\mathrm{K}_{\mathrm{a}}\right)$ is estimated at $>10^{8} \mathrm{M}^{-1}$ [29]. Moreover, consistent with previous observations, the UV spectra do not change with addition of excess metal ion. The spectral changes observed reflect changes to the conformation of the terpyridine group. The coordination to $\mathrm{Zn}^{2+}$ enforces a cis-cis configuration of the three pyridine rings [30]. Because of the similarities between our data and these precedents, we speculate that the $\mathrm{Zn}(9)_{2}{ }^{2+}$ complex likewise adopts a distorted octahedral complex [29]. Ongoing studies will evaluate the relative importance of the presence of a high-affinity ligand such as terpyridine and the scaffold flexibility to metal coordination. Indeed, linear azole peptoids show temperature-induced changes to their ${ }^{1} \mathrm{H}-\mathrm{NMR}$ spectra, confirming their conformational heterogeneity (see Supplementary Materials). Future studies will pursue the ability of more highly-structured oligomers based on the azole peptoid scaffold, including macrocycles, to bind metals.

In summary, we have introduced a new class of peptidomimetic, the azole peptoid, and have demonstrated one potential application of these molecules for coordinating to transition metals in water. The similarities between the azole peptoids and azole-rich natural products make it an attractive scaffold for a range of uses. We anticipate that the straightforward, flexible methods reported here for the synthesis of diversely functionalized azole peptoid analogs will facilitate access to custom-functionalized analogs for further study. Ongoing work in our laboratory will continue to explore relationships between the structures of azole peptoid examples and their capacity to coordinate transitions metals.

\section{Materials and Methods}

\subsection{General Experimental Information}

Compounds $1 \mathbf{a}$ and $\mathbf{1 b}$ were prepared as described in the literature, and their spectral features were identical to those reported [24]. 2-(2,2':6', $2^{\prime \prime}$-Terpyridine-4'-yloxyl)ethylamine was also prepared 
according to literature procedures, and its spectral features were identical to those reported [9]. 2-Chlorotrityl chloride resin was purchased from ChemPep. All other reagents and solvents were purchased from commercial sources and used without further purification. ${ }^{1} \mathrm{H}$ and ${ }^{13} \mathrm{C}-\mathrm{NMR}$ spectra were recorded on a $400 \mathrm{MHz}$ spectrometer using a 5-mm high-resolution direct-detection probe. Chemical shifts $(\delta)$ are reported in parts per million (ppm) and are referenced to residual proton in the deuterated solvent, and spectra were acquired at room temperature for compound characterization. Owing to the presence of multiple rotameric states as detailed in the text, all ${ }^{1} \mathrm{H}$-NMR spectra show poor signal dispersion, and peaks appear as complex multiplets. ${ }^{13} \mathrm{C}-\mathrm{NMR}$ spectra also show broadened and multiple peaks for carbons attributed to different rotamers. The molar masses of purified peptoids were confirmed by electrospray mass spectrometry in positive ion mode. High-resolution mass spectral data were acquired using electrospray ionization and a TOF detector in positive ion mode.

\subsection{Reverse-Phase High-Performance Liquid Chromatography (RP-HPLC)}

The crude purities of the compounds prepared were assessed by analytical RP-HPLC, and products were purified by semi-preparative RP-HPLC. Compounds were eluted from an AAPPTec Spirit Peptide C18 column $(5 \mu \mathrm{M}, 0.46 \mathrm{~cm} \times 15 \mathrm{~cm}$ for analytical or $5 \mu \mathrm{M}, 10.0 \mathrm{~mm} \times 25 \mathrm{~cm}$ for semi-preparative) using a linear gradient of methanol (solvent B) in $0.1 \%$ aqueous TFA (solvent A) at $0.75 \mathrm{~mL} / \mathrm{min}$ (analytical) or $3 \mathrm{~mL} / \mathrm{min}$ (semi-preparative) flow rate. Peaks eluted were detected by absorbance at $220 \mathrm{~nm}$, and data were visualized with EZChrom software. Chromatograms of both crude and purified compounds are shown in the Supplementary Materials. Purified compounds were isolated by lyophilization to afford white powders.

\subsection{General Procedure for Synthesis of N-Benzoylated Azole Peptoid Trimers}

2-Chlorotrityl chloride resin $(137 \mathrm{mg}, 1.1 \mathrm{mmol} / \mathrm{g}, 0.15 \mathrm{mmol})$ was added to a glass peptide synthesis vessel fitted with a coarse glass frit and a Teflon stopcock, rinsed with $\mathrm{CH}_{2} \mathrm{Cl}_{2}(2 \times 2 \mathrm{~mL})$, then swelled for five minutes in $2 \mathrm{~mL} \mathrm{CH} \mathrm{Cl}_{2}$, and drained. In a separate vial, $\mathrm{CH}_{2} \mathrm{Cl}_{2}(1.3 \mathrm{~mL}), \mathbf{1}$ (32 mg 1a or $29 \mathrm{mg} \mathrm{1b}, 0.18 \mathrm{mmol}, 1.2$ equiv), and $N, N$-diisopropylethylamine (DIEA) $(0.126 \mathrm{~mL}$, $0.72 \mathrm{mmol}, 4.8$ equiv) were mixed and then added to the synthesis vessel. The mixture was agitated at room temperature for $1 \mathrm{~h}$, drained, and washed with $\mathrm{CH}_{2} \mathrm{Cl}_{2}(3 \times 2 \mathrm{~mL})$ then DMSO $(3 \times 2 \mathrm{~mL})$. A solution of the appropriate primary amine $(3 \mathrm{~mL}, 2 \mathrm{M}$ in DMSO, 20 equivalents) was added to the reaction vessel, and the reaction mixture was heated in a sand bath at $50{ }^{\circ} \mathrm{C}$ for $1 \mathrm{~h}$. The resin was drained and washed with DMSO $(3 \times 2 \mathrm{~mL})$, and then NMP $(3 \times 2 \mathrm{~mL})$. A chloranil test was performed to confirm the presence of a secondary amine (beads turned blue/green).

In a separate vial, $\mathbf{1}(68 \mathrm{mg} \mathbf{1 a}$ or $61 \mathrm{mg} \mathbf{1 b}, 0.38 \mathrm{mmol}, 2.5$ equiv), NMP (0.38 mL), COMU (187 mg, $0.44 \mathrm{mmol}, 2.9$ equiv), and DIEA $(0.157 \mathrm{~mL}, 0.90 \mathrm{mmol}, 6$ equiv) were mixed, and the resulting bright red solution was agitated for $5 \mathrm{~min}$ before being added to the reaction vessel. The mixture was then agitated for an additional $20 \mathrm{~min}$ at room temperature, drained, and washed with NMP $(5 \times 2 \mathrm{~mL})$ and DMSO $(3 \times 2 \mathrm{~mL})$. A chloranil test was performed to confirm the absence of a secondary amine (beads remained colorless). The addition of primary amine, washing, then acylation with $\mathbf{1 a}$ or $\mathbf{1} \mathbf{b}$ was iterated to generate trimers. Following the third and final primary amine addition, the resultant secondary amine was reacted with benzoyl chloride $\left(0.060 \mathrm{~mL}, 0.52 \mathrm{mmol}, 3.5\right.$ equiv) in $\mathrm{CH}_{2} \mathrm{Cl}_{2}(0.52 \mathrm{~mL})$ and DIEA ( $0.181 \mathrm{~mL}, 1.04 \mathrm{mmol}, 6.9$ equiv). The mixture was agitated for $15 \mathrm{~min}$ at room temperature, drained, and washed with $\mathrm{CH}_{2} \mathrm{Cl}_{2}$-DIEA 4:1 $(3 \times 1 \mathrm{~mL}), \mathrm{CH}_{2} \mathrm{Cl}_{2}(3 \times 2 \mathrm{~mL}), \mathrm{NMP}(3 \times 2 \mathrm{~mL})$, and $\mathrm{CH}_{2} \mathrm{Cl}_{2}(3 \times 2 \mathrm{~mL})$.

A $1 \mathrm{~mL}$ mixture of 1,1,1,3,3,3-hexafluoro-2-propanol/ $\mathrm{CH}_{2} \mathrm{Cl}_{2}$ (1:4) was added to the resin, effecting a color change to bright red, and the mixture was agitated for $1 \mathrm{~h}$ at room temperature. The solution was then collected by filtration and combined with $\mathrm{CH}_{2} \mathrm{Cl}_{2}$ washes of the resin $(5 \times 2 \mathrm{~mL})$. The collected solution was concentrated via rotary evaporation. The crude residue was dissolved in acetonitrile and water, frozen, and lyophilized prior to analysis. 


\subsection{Data for Azole Peptoids Prepared}

\subsubsection{Thiazole Peptoid Trimer 2a}

The general procedure was followed, using $\mathbf{1 a}$ and 4-(2-aminoethyl)morpholine. Following purification by RP-HPLC using 20-50\% gradient of solvent B in solvent A, $80 \mathrm{mg}$ (61\%) 2a were isolated as a white powder. ${ }^{1} \mathrm{H}-\mathrm{NMR}\left(400 \mathrm{MHz}, \mathrm{CD}_{3} \mathrm{CN}\right) \delta 12.71-10.33$ (br s, $\left.1 \mathrm{H}\right)$, 8.60-7.74 (m, 3H), 7.74-7.03 (m, 5H), 6.07-4.45 (m, 7H), 4.44-2.42 (m, 35H); ${ }^{13} \mathrm{C}-\mathrm{NMR}(100 \mathrm{MHz}$, $\left.\mathrm{CD}_{3} \mathrm{CN}\right) \delta 172.6,169.8,167.2,165.6,164.0163 .8,163.3,162.4,160.7,160.3,160.0,159.6,148.3,147.8,146.8$, 134.6, 134.5, 130.0, 128.9, 128.2, 128.1, 127.9, 127.5, 127.4, 126.4, 120.6, 117.7, 114.8, 111.9, 63.3, 63.0, 60.5, 54.0, 53.9, 53.7, 51.9, 51.8, 50.6, 50.5, 50.0, 47.7, 47.2, 43.5, 42.9, 42.0, 41.8, 41.4, 40.0, 29.0, 27.1; HRMS (ESI-TOF) $m / z$ calculated for $\left[\mathrm{C}_{40} \mathrm{H}_{52} \mathrm{~N}_{9} \mathrm{O}_{8} \mathrm{~S}_{3}\right]^{+} 881.302$, found 881.303.

\subsubsection{Oxazole Peptoid Trimer $\mathbf{2 b}$}

The general procedure was followed, using $\mathbf{1 b}$ and 4-(2-aminoethyl)morpholine. Following purification by RP-HPLC using 10-50\% gradient of solvent B in solvent A, $43 \mathrm{mg}$ $(33 \%) 2 b$ were isolated as a white powder. ${ }^{1} \mathrm{H}-\mathrm{NMR}\left(400 \mathrm{MHz}, \mathrm{CD}_{3} \mathrm{CN}\right) \delta 11.98-9.64$ (br s, $\left.1 \mathrm{H}\right)$, 8.45-8.09 (m, 3H), 7.62-7.27 (m, 5H), 5.40-4.27 (m, 13H), 4.27-2.75 (m, 30H); ${ }^{13} \mathrm{C}-\mathrm{NMR}(100 \mathrm{MHz}$, $\left.\mathrm{CD}_{3} \mathrm{CN}\right) \delta 162.4,160.6,160.3,159.9,145.6,145.3,144.7,135.3,134.5,129.9,128.2,126.3,117.9,115.0$, 63.4, 63.3, 63.0, 54.4, 54.3, 53.9, 53.7, 53.5, 53.3, 52.2, 51.8, 51.7, 48.6, 46.4, 46.0, 42.5, 42.0, 40.0, 29.6, 29.0; HRMS (ESI-TOF) $m / z$ calculated for $\left[\mathrm{C}_{40} \mathrm{H}_{52} \mathrm{~N}_{9} \mathrm{O}_{11}+\mathrm{H}\right]^{+} 833.371$, found 833.371.

\subsubsection{Thiazole Peptoid Trimer 3a}

The general procedure was followed, using 1a and 2-methoxyethylamine. Following purification by RP-HPLC using 55-80\% gradient of solvent B in solvent A, $18 \mathrm{mg}$ (13\%) 3a were isolated as a white powder. ${ }^{1} \mathrm{H}-\mathrm{NMR}\left(400 \mathrm{MHz}, \mathrm{CD}_{3} \mathrm{CN}\right) \delta 8.19-7.81(\mathrm{~m}, 3 \mathrm{H}), 7.46-7.05(\mathrm{~m}, 5 \mathrm{H}), 5.39-4.50(\mathrm{~m}, 6 \mathrm{H})$, 3.96-2.80 (m, 22H); ${ }^{13} \mathrm{C}-\mathrm{NMR}\left(100 \mathrm{MHz}, \mathrm{CD}_{3} \mathrm{CN}\right) \delta 172.6,170.7,168.4,167.5,166.9,166.8,165.5,163.6$, $163.2,162.6,160.7,160.4,160.0,148.9,148.0,147.2,134.5,130.0,128.3,128.0,126.9,126.5,126.2,120.9$, 118.0, 115.0, 112.1, 78.11, 73.4, 71.6, 71.2, 70.0, 69.7, 63.2, 63.0, 57.8, 57.7, 54.0, 53.6, 51.7, 50.2, 49.0, 48.8, 48.6, 48.3, 47.5, 46.2, 43.6, 41.5, 39.5; HRMS (ESI-TOF) $m / z$ calculated for $\left[\mathrm{C}_{31} \mathrm{H}_{37} \mathrm{~N}_{6} \mathrm{O}_{8} \mathrm{~S}_{3}\right]^{+} 716.176$, found 716.178 .

\subsubsection{Oxazole Peptoid Trimer $3 \mathrm{~b}$}

The general procedure was followed, using $\mathbf{1 b}$ and 2-methoxyethylamine. Following purification by RP-HPLC using 40-80\% gradient of solvent B in solvent A, $31 \mathrm{mg}(31 \%) 3 \mathrm{~b}$ were isolated as a white powder. ${ }^{1} \mathrm{H}-\mathrm{NMR}\left(400 \mathrm{MHz}, \mathrm{CD}_{3} \mathrm{CN}\right) \delta 8.38-8.08(\mathrm{~m}, 3 \mathrm{H}), 7.53-7.22(\mathrm{~m}, 5 \mathrm{H}), 5.41-4.42(\mathrm{~m}, 7 \mathrm{H})$, 4.21-2.94 (m, 29H); ${ }^{13} \mathrm{C}-\mathrm{NMR}\left(100 \mathrm{MHz}, \mathrm{CD}_{3} \mathrm{CN}\right) \delta 163.3,162.7,162.4,161.5,160.11,159.7,145.9,145.1$, 137.2, 136.9, 133.9, 130.7, 129.5, 127.9, 121.0, 115.3, 72.6, 71.3, 71.2, 59.1, 50.2, 59.9, 49.7, 48.1, 47.8, 47.7, 46.4, 45.0, 43.2, 30.4; HRMS (ESI-TOF) $m / z$ calculated for $\left[\mathrm{C}_{31} \mathrm{H}_{37} \mathrm{~N}_{6} \mathrm{O}_{11}\right]^{+}$668.244, found 668.241.

\subsubsection{Thiazole Peptoid Trimer $4 \mathbf{a}$}

The general procedure was followed, using 1a and 3-(aminomethyl)pyridine. Following purification by RP-HPLC using 25-30\% gradient of solvent B in solvent A, $62 \mathrm{mg}$ (51\%) 4a were isolated as a white powder. ${ }^{1} \mathrm{H}-\mathrm{NMR}\left(400 \mathrm{MHz}, \mathrm{CD}_{3} \mathrm{OD}\right) \delta$ 9.16-7.78 (m, 15H), 7.58-7.08 (m, 5H), 5.63-4.51 (m, 12H, overlapping with HOD peak); ${ }^{13} \mathrm{C}-\mathrm{NMR}\left(100 \mathrm{MHz}, \mathrm{CD}_{3} \mathrm{OD}\right) \delta 174.5,169.8,167.9,167.6,165.4,165.3,164.0$, $162.6,159.7,159.3,158.9,158.5,149.9,149.4,148.3,147.9,146.2,145.5,144.0,143.6,143.0,138.9,135.9,132.0$, 131.1, 130.7, 130.4, 130.1, 127.94, 127.91, 122.4, 120.4, 119.5, 117.6, 116.6, 114.8, 111.9, 91.2, 55.06, 54.8, 54.6, $54.4,54.2,52.3,51.8,51.5,49.4,49.2$ (other peaks likely obscured by solvent resonances); HRMS (ESI-TOF) $m / z$ calculated for $\left[\mathrm{C}_{40} \mathrm{H}_{34} \mathrm{~N}_{9} \mathrm{O}_{5} \mathrm{~S}_{3}\right]^{+}$816.184, found 816.184. 


\subsubsection{Oxazole Peptoid Trimer $\mathbf{4 b}$}

The general procedure was followed, using $\mathbf{1 b}$ and 3-(aminomethyl)pyridine. Following purification by RP-HPLC using 20-55\% gradient of solvent $\mathrm{B}$ in solvent A, $56 \mathrm{mg}(48 \%) 4 \mathrm{~b}$ were isolated as a white powder. ${ }^{1} \mathrm{H}-\mathrm{NMR}\left(400 \mathrm{MHz}, \mathrm{CD}_{3} \mathrm{OD}\right) \delta 9.14-8.21(\mathrm{~m}, 12 \mathrm{H}), 8.15-7.75(\mathrm{~m}, 3 \mathrm{H}), 7.63-7.13(\mathrm{~m}, 5 \mathrm{H}), 5.57-4.48$ (m, 12H, overlapping with HOD peak); ${ }^{13} \mathrm{C}-\mathrm{NMR}\left(100 \mathrm{MHz}, \mathrm{CD}_{3} \mathrm{OD}\right) \delta 174.7,164.2,163.9,163.7,162.8$, 161.5, 159.3, 158.9, 147.8, 146.8, 146.4, 144.3, 138.7, 137.10, 135.8, 134.9, 134.5, 133.3, 132.0, 130.1, 129.9, 128.6, 127.9, 119.6, 117.6, 116.7, 114.8, 111.9, 51.8, 51.6, 51.5, 49.9, 49.7, 49.4, 49.2, 19.0, 48.1, 44.7, 30.9; HRMS (ESI-TOF) $m / z$ calculated for $\left[\mathrm{C}_{40} \mathrm{H}_{34} \mathrm{~N}_{9} \mathrm{O}_{8}\right]^{+} 768.253$, found 768.254 .

\subsubsection{Thiazole Peptoid Trimer 5}

The general procedure was followed, using 1a and 4-phenylbutylamine. Following purification by RP-HPLC using 70-100\% gradient of solvent B in solvent A, $56 \mathrm{mg}(40 \%) 5$ were isolated as a white powder. ${ }^{1} \mathrm{H}-\mathrm{NMR}\left(400 \mathrm{MHz}, \mathrm{CD}_{3} \mathrm{CN}\right) \delta 8.25-7.82(\mathrm{~m}, 3 \mathrm{H}), 7.56-6.56(\mathrm{~m}, 20 \mathrm{H}), 5.31-4.45(\mathrm{~m}, 6 \mathrm{H})$, 3.89-3003 (m, 6H), 2.74-2.15 (m, 6H), 1.81-0.94 (m, 12H); ${ }^{13} \mathrm{C}-\mathrm{NMR}\left(100 \mathrm{MHz}, \mathrm{CD}_{3} \mathrm{CN}\right) \delta 172.6,170.6$, 169.3, 169.1, 168.3, 168.0, 167.7, 164.7, 163.9, 162.6, 150.3, 147.3, 147.0, 143.5, 143.4, 143.1, 137.2, 130.6, $130.5,130.3,129.6,129.3,129.4,127.9,127.5,126.8,126.7,51.5,51.4,51.0,50.7,49.2,49.0,48.7,47.8,36.1$, 35.8, 30.4, 29.7, 29.5, 29.3, 29.0, 27.6; HRMS (ESI-TOF) $m / z$ calculated for $\left[\mathrm{C}_{52} \mathrm{H}_{55} \mathrm{~N}_{6} \mathrm{O}_{5} \mathrm{~S}_{3}\right]^{+}$938.332, found 938.332 .

\subsubsection{Thiazole Peptoid Trimer 6}

The general procedure was followed, using $1 \mathrm{a}$ and isopropylamine. Following purification by RP-HPLC using $50-80 \%$ gradient of solvent B in solvent A, $15 \mathrm{mg}(15 \%) 6$ were isolated as a white powder. ${ }^{1} \mathrm{H}-\mathrm{NMR}\left(400 \mathrm{MHz}, \mathrm{CD}_{3} \mathrm{CN}\right) \delta 8.27-8.11$ (br s, $\left.1 \mathrm{H}\right), 8.03-7.74(\mathrm{~m}, 2 \mathrm{H}), 7.61-7.23(\mathrm{~m}, 5 \mathrm{H})$, 6.96-5.81 (br s, 5H), 5.41-4.40 (m, 8H), 4.20-3.83 (br s, 1H), 1.49-0.72 (m, 18H); ${ }^{13} \mathrm{C} \mathrm{NMR} \mathrm{(100} \mathrm{MHz,}$ $\left.\mathrm{CD}_{3} \mathrm{CN}\right) \delta 172.7,171.2,169.9,169.7,165.8,162.4,159.7,159.3,150.3,149.9,146.4,137.6,130.6,130.3$, 129.7, 127.2, 125.4, 125.1, 120.8, 115.1, 52.0, 51.4, 48.7, 47.3, 43.9, 43.7, 43.2, 30.4, 21.6, 21.3, 20.3; HRMS (ESI-TOF) $m / z$ calculated for $\left[\mathrm{C}_{31} \mathrm{H}_{37} \mathrm{~N}_{6} \mathrm{O}_{5} \mathrm{~S}_{3}+\mathrm{H}\right]^{+}$668.191, found 668.192.

\subsubsection{Thiazole Peptoid Trimer 7}

The general procedure was followed, using 1a and 4-(2-aminoethyl)morpholine and tert-butyl $\mathrm{N}$-(2-aminoethyl)carbamate with the following exception. Following $\mathrm{N}$-benzoylation, a solution of 95\% TFA, 2.5\% water, and 2.5\% triisopropylsilane was added to the resin, and the mixture was gently agitated, then allowed to sit for $1 \mathrm{~h}$ at room temperature. The solution and $\mathrm{CH}_{2} \mathrm{Cl}_{2}$ washes were then combined, concentrated by rotary evaporation, then dissolved in acetonitrile and water, frozen, and lyophilized. Following purification by RP-HPLC using 20-40\% gradient of solvent B in solvent A, $59 \mathrm{mg}$ (63\%) 7 were isolated as a white powder. ${ }^{1} \mathrm{H}-\mathrm{NMR}\left(400 \mathrm{MHz}, \mathrm{CD}_{3} \mathrm{CN}\right) \delta 11.92-9.55$ (br s, 3H), 8.48-7.73 $(\mathrm{m}, 6 \mathrm{H}), 7.61-7.16(\mathrm{~m}, 5 \mathrm{H}), 5.61-4.56(\mathrm{~m}, 6 \mathrm{H}), 4.38-2.68(\mathrm{~m}, 28 \mathrm{H}) ;{ }^{13} \mathrm{C}-\mathrm{NMR}\left(100 \mathrm{MHz}, \mathrm{CD}_{3} \mathrm{CN}\right) \delta 173.8$, 173.0, 170.5, 168.0, 165.5, 165.4, 164.5, 162.1, 161.8, 161.4, 161.1, 149.8, 149.3, 148.8, 136.0, 131.4, 129.6, $128.8,127.9,122.0,119.2,116.2,113.3,64.7,64.5,55.2,54.9,53.2,51.9,51.5,48.6,44.7,42.9,42.5,41.4,39.4$, 38.6, 30.4; HRMS (ESI-TOF) $m / z$ calculated for $\left[\mathrm{C}_{36} \mathrm{H}_{46} \mathrm{~N}_{9} \mathrm{O}_{7} \mathrm{~S}_{3}\right]^{+} 812.268$, found 812.268.

\subsubsection{Thiazole Peptoid Trimer 8}

The general procedure was followed, using $1 \mathrm{a}$ and propargylamine, 2-methoxyethylamine, and 4-(2-aminoethyl)morpholine. Following purification by RP-HPLC using 30-90\% gradient of solvent $\mathrm{B}$ in solvent A, $44 \mathrm{mg}(39 \%) 8$ were isolated as a white powder. ${ }^{1} \mathrm{H}-\mathrm{NMR}\left(400 \mathrm{MHz}, \mathrm{CD}_{3} \mathrm{CN}\right) \delta$ 8.29-8.12 (m, 1H), 8.11-7.92 (m, 2H), 7.55-7.18 (m, 5H), 5.49-4.69 (m, 7H), 4.03-2.89 (m, 23H); ${ }^{13} \mathrm{C}-\mathrm{NMR}$ $\left(100 \mathrm{MHz}, \mathrm{CD}_{3} \mathrm{CN}\right) \delta 173.6,170.0,168.9,165.8,164.8,163.7,162.1,161.8,150.7,147.9,137.6,131.2,130.7$, 130.0, 128.5, 127.9, 127.7, 73.0, 71.7, 71.5, 59.6, 53.1, 52.7, 50.9, 50.6, 50.4, 48.1; HRMS (ESI-TOF) $m / z$ calculated for $\left[\mathrm{C}_{34} \mathrm{H}_{38} \mathrm{~N}_{7} \mathrm{O}_{7} \mathrm{~S}_{3}\right]^{+}$751.192, found 751.192. 


\subsubsection{Thiazole Peptoid Trimer 9}

The general procedure was followed with modifications as noted below using $\mathbf{1 a}$ and 2-methoxyethylamine, and 2-(2,2':6', $2^{\prime \prime}$-Terpyridine- $4^{\prime}$-yloxyl)ethylamine. Following benzoylation of the $N$-terminus and subsequent washing steps, $2 \mathrm{~mL}$ of a $20 \%$ solution of 4 -methylpiperidine in DMF was added to reverse undesired benzoylation of the terpyridine side chain. The reaction vessel was shaken for $20 \mathrm{~min}$, then the resin was washed with DMF before cleaving 9 from the resin as described in the general procedure. Following purification by RP-HPLC using 50-80\% gradient of solvent B in solvent A, $83 \mathrm{mg}(30 \%) 9$ were isolated as a white powder. ${ }^{1} \mathrm{H}-\mathrm{NMR}\left(400 \mathrm{MHz}, \mathrm{CD}_{3} \mathrm{CN}\right) \delta 11.40$ (br s, $1 \mathrm{H}), 9.09,(\mathrm{~d}, 2 \mathrm{H}), 8.80-8.40(\mathrm{~m}, 4 \mathrm{H}), 8.24-7.68(\mathrm{~m}, 7 \mathrm{H}), 7.61-7.32(\mathrm{~m}, 5 \mathrm{H}), 5.48-3.05(\mathrm{~m}, 24 \mathrm{H}) ;{ }^{13} \mathrm{C}-\mathrm{NMR}$ $\left(100 \mathrm{MHz}, \mathrm{CD}_{3} \mathrm{CN}\right) \delta 171.7,167.9,166.3,163.7,162.5,161.5,160.1,159.8,159.4,159.1,149.3,148.5,147.3$, $145.9,144.7,144.4,135.3,129.5,128.6,128.3,127.3,126.6,126.0,123.9,120.4,117.5,114.6,111.7,110.3$, $70.9,69.7,66.8,57.7,51.0,50.8,48.4,47.8,46.2$; HRMS (ESI-TOF) $m / z$ calculated for $\left[\mathrm{C}_{45} \mathrm{H}_{44} \mathrm{~N}_{9} \mathrm{O}_{8} \mathrm{~S}_{3}\right]^{+}$ 934.247, found 934.246 .

\subsection{Evaluation of $\mathrm{Zn}^{2+}$ Binding by 9}

\subsubsection{Preparation of a Stock Solution of 9}

A precisely-weighed quantity of purified, lyophilized thiazole peptoid 9 was dissolved in 1:1 dioxane:water at an approximate concentration of $5 \mathrm{mM}$. Additional small volumes of $10 \mathrm{mM}$ Tris buffer, pH 7.5 were added gradually to effect complete dissolution of $\mathbf{9}$, and the final concentration was determined from the mass of $\mathbf{9}$ and the total volume of solution.

\subsection{2. $\mathrm{Zn}^{2+}$ Titrations to 9 Monitored by UV-Vis Spectroscopy}

Solutions of $50 \mu \mathrm{M} 9$ (diluted from the stock) and 0-150 $\mu \mathrm{M}$ and $\mathrm{ZnCl}_{2}$ (diluted from a $5 \mathrm{mM}$ stock solution in $10 \mathrm{mM}$ Tris buffer, $\mathrm{pH}$ 7.5) were prepared in $10 \mathrm{mM}$ Tris buffer, $\mathrm{pH} 7.5$ to a final volume of $500 \mu \mathrm{L}$. Each solution was mixed well, then $150 \mu \mathrm{L}$ was distributed to each of three wells in a transparent flat bottom, low volume, acrylic 96-well plate. The UV-Visible spectrum was recorded for each well of the plate by a Molecular Devices SpectraMax i3x plate reader. Spectra were collected from $230 \mathrm{~nm}$ to $900 \mathrm{~nm}$ every $1 \mathrm{~nm}$. Spectra were averaged for the three wells containing identical solutions.

Supplementary Materials: The following are available online. Scheme S1: Synthesis of functionalized azole building blocks 1a and 1b. Figure S1: Crude analytical HPLC chromatograms, Figure S2: Analytical HPLC chromatograms of purified compounds, Figure S3: ${ }^{1} \mathrm{H}$ and ${ }^{13} \mathrm{C}-\mathrm{NMR}$ spectra of 2-9, Figure S4: UV spectra of 3a in the presence of increasing $\left[\mathrm{Zn}^{2+}\right]$, Figure S5: Variable temperature ${ }^{1} \mathrm{H}-\mathrm{NMR}$ spectra of 6 .

Author Contributions: A.A.F. conceived and designed the experiments; A.M., A.H.M.K., G.G., A.L.C. and K.N.M. performed the experiments; A.A.F, A.M. and A.L.C. analyzed the data; A.A.F. wrote the paper.

Acknowledgments: The work described was supported by awards from the National Science Foundation (CHE-1056520 and CHE-1566604) and the Clare Booth Luce Foundation. A.H.M.K. was supported by a DeNardo Science Scholar Award, and K.N.M. was supported by the Johnson Leadership Stipend from Santa Clara University. Routine mass spectra were obtained using an instrument funded by NSF MRI 1126895, and NMR data were obtained on an instrument funded by NSF MRI 0923575. The authors also wish to acknowledge Korin E. Wheeler for many helpful discussions and Brandon White for assistance with high resolution mass spectrometry at the PROTEIN lab at San Jose State University (NSF MRI 0923573). Santa Clara University provided funding to cover costs for open access publication.

Conflicts of Interest: The authors declare no conflict of interest. The founding sponsors had no role in the design of the study; in the collection, analyses, or interpretation of data; in the writing of the manuscript, and in the decision to publish the results.

\section{References}

1. Knight, A.S.; Kulkarni, R.U.; Zhou, E.Y.; Franke, J.M.; Miller, E.W.; Francis, M.B. A modular platform to develop peptoid-based selective fluorescent metal sensors. Chem. Commun. 2017, 53, 3477-3480. [CrossRef] [PubMed] 
2. Maayan, G. Conformational control in metallofoldamers: Design, synthesis and structural properties. Eur. J. Org. Chem. 2009, 2009, 5699-5710. [CrossRef]

3. Prathap, K.J.; Maayan, G. Metallopeptoids as efficient biomimetic catalysts. Chem. Commun. 2015, 51, 11096-11099. [CrossRef] [PubMed]

4. Maayan, G.; Ward, M.D.; Kirshenbaum, K. Folded biomimetic oligomers for enantioselective catalysis. Proc. Natl. Acad. Sci. USA 2009, 106, 13679-13684. [CrossRef] [PubMed]

5. Gellman, S.H. Foldamers: A manifesto. Acc. Chem. Res. 1998, 31, 173-180. [CrossRef]

6. Hill, D.J.; Mio, M.J.; Prince, R.B.; Hughes, T.S.; Moore, J.S. A field guide to foldamers. Chem. Rev. 2001, 101, 3893-4011. [CrossRef] [PubMed]

7. Fowler, S.A.; Blackwell, H.E. Structure-function relationships in peptoids: Recent advances toward deciphering the structural requirements for biological function. Org. Biomol. Chem. 2009, 7, 1508. [CrossRef] [PubMed]

8. Goodman, C.M.; Choi, S.; Shandler, S.; DeGrado, W.F. Foldamers as versatile frameworks for the design and evolution of function. Nat. Chem. Biol. 2007, 3, 252-262. [CrossRef] [PubMed]

9. Maayan, G.; Yoo, B.; Kirshenbaum, K. Heterocyclic amines for the construction of peptoid oligomers bearing multi-dentate ligands. Tetrahedron Lett. 2008, 49, 335-338. [CrossRef] [PubMed]

10. Baskin, M.; Maayan, G. A rationally designed metal-binding helical peptoid for selective recognition processes. Chem. Sci. 2016, 7, 2809-2820. [CrossRef] [PubMed]

11. Bertram, A.; Pattenden, G. Marine metabolites: Metal binding and metal complexes of azole-based cyclic peptides of marine origin. Nat. Prod. Rep. 2007, 24, 18-30. [CrossRef] [PubMed]

12. Van den Brenk, A.L.; Byriel, K.A.; Fairlie, D.P.; Gahan, L.R.; Hanson, G.R.; Hawkins, C.J.; Jones, A.; Kennard, C.H.L.; Moubaraki, B.; Murray, K.S. Crystal structure and electrospray ionization mass spectrometry, electron paramagnetic resonance, and magnetic susceptibility study of $\left[\mathrm{Cu}_{2}\left(\operatorname{ascidH}_{2}\right)\left(1,2-\mu-\mathrm{CO}_{3}\right)\left(\mathrm{H}_{2} \mathrm{O}\right)_{2}\right] \cdot 2 \mathrm{H}_{2} \mathrm{O}$, the bis(copper(II)) complex of ascidiacyclamide $\left(\right.$ ascidH $\left._{4}\right)$, a cyclic peptide isolated from the ascidian Lissoclinum patella. Inorg. Chem. 1994, 33, 3549-3557. [CrossRef]

13. Wipf, P.; Venkatraman, S.; Miller, C.P.; Geib, S.J. Metal complexes of marine peptide metabolites: A novel $\mathrm{Ag}_{4}$ Cluster. Angew. Chem. Int. Ed. Engl. 1994, 33, 1516-1518. [CrossRef]

14. Wipf, P. Synthetic studies of biologically active marine cyclopeptides. Chem. Rev. 1995, 95, $2115-2134$. [CrossRef]

15. Jolliffe, K.A. Backbone-modified cyclic peptides: New scaffolds for supramolecular chemistry. Supramol. Chem. 2005, 17, 81-86. [CrossRef]

16. Dudin, L.; Pattenden, G.; Viljoen, M.S.; Wilson, C. Synthesis of novel N-methylated thiazole-based cyclic octa- and dodecapeptides. Tetrahedron 2005, 61, 1257-1267. [CrossRef]

17. Simon, R.J.; Kania, R.S.; Zuckermann, R.N.; Huebner, V.D.; Jewell, D.A.; Banville, S.; Ng, S.; Wang, L.; Rosenberg, S.; Marlowe, C.K. Peptoids: A modular approach to drug discovery. Proc. Natl. Acad. Sci. USA 1992, 89, 9367-9371. [CrossRef] [PubMed]

18. Zuckermann, R.N. Peptoid origins. Biopolymers 2011, 96, 545-555. [CrossRef]

19. Baskin, M.; Panz, L.; Maayan, G. Versatile ruthenium complexes based on 2,2'-bipyridine modified peptoids. Chem. Commun. 2016, 52, 10350-10353. [CrossRef] [PubMed]

20. Maayan, G.; Ward, M.D.; Kirshenbaum, K. Metallopeptoids. Chem. Commun. 2009, 56-58. [CrossRef] [PubMed]

21. Knight, A.S.; Zhou, E.Y.; Francis, M.B. Development of peptoid-based ligands for the removal of cadmium from biological media. Chem. Sci. 2015, 6, 4042-4048. [CrossRef] [PubMed]

22. Knight, A.S.; Zhou, E.Y.; Pelton, J.G.; Francis, M.B. Selective chromium(VI) ligands identified using combinatorial peptoid libraries. J. Am. Chem. Soc. 2013, 135, 17488-17493. [CrossRef] [PubMed]

23. Lee, B.-C.; Chu, T.K.; Dill, K.A.; Zuckermann, R.N. Biomimetic nanostructures: Creating a high-affinity zinc-binding site in a folded nonbiological polymer. J. Am. Chem. Soc. 2008, 130, 8847-8855. [CrossRef] [PubMed]

24. Aditya, A.; Kodadek, T. Incorporation of heterocycles into the backbone of peptoids to generate diverse peptoid-inspired one bead one compound libraries. ACS Comb. Sci. 2012, 14, 164-169. [CrossRef] [PubMed]

25. Zuckermann, R.N.; Kerr, J.M.; Kent, S.B.H.; Moos, W.H. Efficient method for the preparation of peptoids [oligo(N-substituted glycines)] by submonomer solid-phase synthesis. J. Am. Chem. Soc. 1992, 114, 10646-10647. [CrossRef] 
26. Hjelmgaard, T.; Faure, S.; Staerk, D.; Taillefumier, C.; Nielsen, J. Efficient and versatile COMU-mediated solid-phase submonomer synthesis of arylopeptoids (oligomeric $N$-substituted aminomethyl benzamides). Org. Biomol. Chem. 2011, 9, 6832-6843. [CrossRef] [PubMed]

27. Burkoth, T.S.; Fafarman, A.T.; Charych, D.H.; Connolly, M.D.; Zuckermann, R.N. Incorporation of unprotected heterocyclic side chains into peptoid oligomers via solid-phase submonomer synthesis. J. Am. Chem. Soc. 2003, 125, 8841-8845. [CrossRef] [PubMed]

28. Figliozzi, G.M.; Goldsmith, R.; Ng, S.C.; Banville, S.C.; Zuckermann, R.N. [25] Synthesis of N-substituted glycine peptoid libraries. Methods Enzymol. 1996, 267, 437-447. [CrossRef] [PubMed]

29. Dobrawa, R.; Lysetska, M.; Ballester, P.; Grüne, M.; Würthner, F. Fluorescent supramolecular polymers: Metal directed self-assembly of perylene bisimide building blocks. Macromolecules 2005, 38, 1315-1325. [CrossRef]

30. Nakamoto, K. Ultraviolet spectra and structures of $2,2^{\prime}$-bipyridine and $2,2^{\prime}, 2^{\prime \prime}$-terpyridine in aqueous solution. J. Phys. Chem. 1960, 64, 1420-1425. [CrossRef]

Sample Availability: Samples of the compounds detailed here are available from the authors.

(c) 2018 by the authors. Licensee MDPI, Basel, Switzerland. This article is an open access article distributed under the terms and conditions of the Creative Commons Attribution (CC BY) license (http://creativecommons.org/licenses/by/4.0/). 